\title{
Evaluation of the effectiveness of migrating corrosion inhibitors and hydrophobizers for protection against corrosion of steel reinforcement in concrete using bimetallic batch sensor
}

\author{
D.S. Shevtsov* and I.D. Zarcyn \\ Voronezh State University, Universitetskaya pl., 1, 394006 Voronezh, Russian Federation \\ *E-mail: shevtsov@chem.vsu.ru
}

\begin{abstract}
A method is proposed for quantitative evaluation of the effectiveness of the protective action of hydrophobizers and inhibitors in relation to the corrosion process of reinforcement in reinforced concrete. Surface treatment of reinforced concrete structures with hydrophobizers leads to a significant increase in the specific electrical resistance of the protective layer of concrete. This makes it difficult to use electrochemical methods to determine the rate of corrosion of reinforcement, in particular, the method of polarization resistance. In this work, as a sensor for determining the rate of corrosion under a layer of concrete, it is proposed to use a bimetallic batch sensor - a package of galvanic cells (copper/low-carbon steel) capable of generating an electric current upon contact with the electrolyte. In this case, the copper plates of the sensor correspond to passive, steel active sections on the surface of the steel reinforcement, and the magnitude of the current between the artificial cathode and anode can be considered as a measure of the corrosion rate of the reinforcement. The distance between the sensor plates is comparable to the distance between individual pits. Therefore, using the above described method, the corrosion process is modeled on the "active" sections of steel reinforcement, areas of microcell-pit/passive steel surfaces. The effectiveness of this method is demonstrated by the example of a commercial hydrophobizer based on alkoxysilanes, which also possesses inhibitory properties. Surface treatment of concrete samples contaminated with chlorides (1.00 and 3.25 mass\% relative to the dry cement mass), a hydrophobizer, leads to a sharp decrease (up to $90 \%$ ) of the galvanic current at the sensor. The protective effect persists for twenty cycles of wetting / drying (10 months) and when the water in the humidification cycle is replaced with a $3 \%$ solution of sodium chloride (six cycles of wetting / drying). When processing a concrete sample with a hydrophobizer, a sharp increase in the specific electrical resistance of concrete (up to 20 times on samples contaminated with chlorides) is observed and the potential for free corrosion of steel plates shifts to positive values. At the same time, the values of the potential of free corrosion and concrete resistivity of concrete, for the passive and active states determined by the sensor, meet the criteria given in RILEMTC 154-EMC. It is shown in the model calculations that an increase in the specific
\end{abstract}


electrical resistance of the protective layer of concrete up to 10-20 times using a hydrophobizer cannot explain the significant reduction in the corrosion rate (galvanic current at the sensor). It is suggested that a consistent change in corrosion rate and resistivity of the protective layer of concrete is due to a similar dependence of these values on the degree of filling of pores in the concrete with water.

Received: July 10, 2018. Published: September 4, 2018

doi: $\underline{10.17675 / 2305-6894-2018-7-3-12}$

Keywords: corrosion of reinforcement in concrete monitoring, batch bimetal sensor, secondary protection of concrete, hydrophobizer, penetrating corrosion inhibitor.

\section{Introduction}

For over a hundred years, reinforced concrete is the most common building material in the world. The chemical and physical properties of concrete ensure the protection of steel reinforcement against corrosion for a long time, up to 50 years or more [1]. However, often many designs come in a condition requiring expensive repairs, after a short period of operation less than ten years [2]. The main reason for this is corrosion of steel reinforcement.

The high $\mathrm{pH}$ of the pore fluid causes the passive state of steel in the concrete. Passive state can be violated in the presence of aggressive ions (in particular chlorides). Reducing the $\mathrm{pH}$ of a pore fluid when interacting with atmospheric carbon dioxide (carbonization) can also be a cause of a passivity disorder. Currently, the costs of repair and restoration of reinforced concrete structures constitute the bulk of the cost of infrastructure facilities in countries with developed market economies [3].

A promising way to reduce the cost of repair and restoration works is based on the introduction of systems for continuous monitoring of the condition of the reinforcement and early detection of the corrosion process. When detecting a violation of the passive state, migratory corrosion inhibitors and deep penetration hydrophobizers are used. These substances reduce the corrosion rate of the reinforcement to a safe level (the so-called proactive approach). Wherein it is possible to avoid expensive repair and restoration works. A correct assessment of the ability of various substances to suppress the corrosion of reinforcement when applied to the surface of reinforced concrete, especially on structures with a high chloride ion content, is the methodological basis for the successful application of a pro-active approach to real objects [4-6].

To quickly assess the effectiveness of migrating inhibitors and hydrophobizers, electrochemical methods are used, most often the polarization resistance method [7,8]. Electrochemical measurements are performed either in model electrolytes simulating a pore liquid, or on electrodes embedded in concrete [7-12]. The ability of various substances to migrate through the protective layer of concrete to the reinforcement, which 
is a prerequisite for the manifestation of their protective action, is studied using membranes made of concrete and precision analytical methods.

The greatest difficulties arise in the study of the protective action of substances combining inhibitory and hydrophobic properties. Hydrophobization of concrete is accompanied by an increase in its specific electrical resistance of concrete. This greatly complicates the use of electrochemical methods. Measurements in model solutions are impossible, due to the extremely low solubility of such substances.

The purpose of the work: the justification of the method for assessing the protective effect of migrating inhibitors combining hydrophobizing and inhibiting properties, with respect to the corrosion process of reinforcement in reinforced concrete structures previously contaminated with chloride ions.

As a sensor for determining the rate of corrosion under a layer of concrete, it is proposed to use a bimetallic package sensor [13]. The device is a set of plates of lowcarbon steel and copper with a thickness of 0.25 and $0.10 \mathrm{~mm}$, respectively, separated by a layer of dielectric - a mica plate with a thickness of $0.10 \mathrm{~mm}$ (Figure 1). The conclusions of homogeneous metals are combined among themselves. The sensor is a package of galvanic cells capable of generating an electric current upon contact with the electrolyte. The magnitude of the current $\left(i_{\text {sensor }}\right)$ is determined by the kinetics of the cathode and anode processes and by the ohmic drop in voltage between the plates. The value of $i_{\text {sensor }}$ was calculated relative to the geometric area of the steel plates.

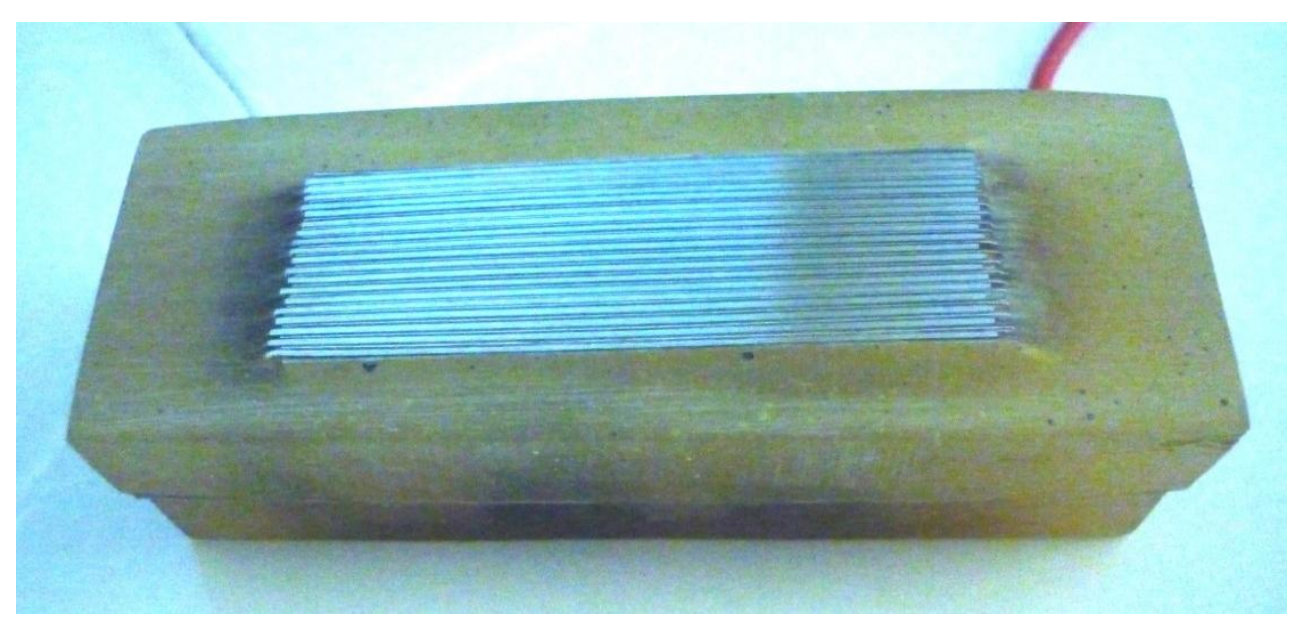

Figure 1. Bimetallic batch sensor.

In [13] the results of experiments are presented, during which the above-described sensor was placed in an electrolyte - an aqueous extract from finely divided concrete, simulating a pore fluid with the addition of chloride ions at various concentrations. When the steel is in a passive state, the potentials for free corrosion of copper and steel are close, the polarization resistance of the anode process on steel is large, the value of $i_{\text {sensor }}$ is small, i.e., less than $2 \mu \mathrm{A} \cdot \mathrm{cm}^{-2}$. With an increase in the concentration of sodium chloride in the 
electrolyte, the steel becomes active and the value of $i_{\text {sensor }}$ increases sharply. In this case, the copper plates of the sensor correspond to passive, steel - active sections on the surface of the steel reinforcement, and the magnitude of the current between the artificial cathode and anode can be considered as a measure of the corrosion rate of the reinforcement. It should be noted that in the absence of chloride ions in the model solution and the magnitude of the free corrosion potential of steel corresponding to the passive state, the value of $i_{\text {sensor }}$ is significantly higher than the values of $0.1-0.2 \mu \mathrm{A} \cdot \mathrm{cm}^{-2}$ given in the literature [11]. This may be due to both significant polarization of the steel with electrical contact with copper, the difference in potentials of free corrosion of these metals under experimental conditions is of the order of $200 \mathrm{mV}$. The reason for increasing the current in the passive state can also be a significant edge effect in the case of an electrode made up of thin steel plates. At the edges of the plates, the passivation film is more defective than on the plane, so the dissolution rate is higher. Subsequently, the excess of $i_{\text {sensor }}$ of $2 \mu \mathrm{A} \cdot \mathrm{cm}^{-2}$ was interpreted as the transition of steel from passive to active state.

The distance between the sensor plates is comparable in order of magnitude with the distance between individual pits. Therefore, using the above described method, the corrosion process is modeled on the "active" sections of steel reinforcement, the areas of microcell functioning. Macrocell in the reinforced concrete structure are formed between the "active" and passive sections of the armature and are characterized by distances between the cathode and the anode of the order of $1 \mathrm{~cm}$ or more, depending on the specific electrical resistance of concrete.

\section{Experimental}

The sensors were placed in fine-grained concrete on the basis of a cement-sand mixture in a ratio of $1 / 3$ by mass. Portland cement of M-500 grade according to GOST 10178-85 and quartz sand was used. The water/cement ratio is 0.4. Stacking the mixture was done in the formwork. Curing took place for 28 days under standard conditions: the first 7 days in the formwork, insulated with a polymer film, then in a chamber with $100 \%$ relative humidity. Thus, concrete prisms measuring $160 \times 40 \times 40 \mathrm{~mm}$ with a thickness of the protective layer of concrete above the working surface of the sensor of $20 \mathrm{~mm}$ were obtained (Figure 2). To accelerate the corrosion process, in the production of a part of the samples, chloride ions were introduced in the form of sodium chloride together with the water of mixing in the amount (mass\%): $0.00 ; 0.10 ; 0.40 ; 1.00$ and 3.25 relative to the dry cement mass.

The experiment on concrete samples with an integrated sensor consisted of forced moisturizing/drying cycles under natural conditions (laboratory atmosphere). In the humidification cycle, for eight hours, the concrete was saturated with distilled water sprayed from the nebulizer with a periodicity of one hour. In intervals between moistening, the samples were placed in a desiccator with $100 \%$ relative humidity. Then, the concrete prisms were left in the desiccator for $12-15$ hours, after which they were removed to the 
air-dry atmosphere of the laboratory (air temperature $22 \pm 30^{\circ} \mathrm{C}$, relative air humidity $34 \pm 2 \%)$. Throughout the experiment, the current $\left(i_{\text {sensor }}\right)$ was fixed, the potential for free corrosion $\left(E_{\text {cor }}\right)$, and the specific electrical resistance of concrete $(\rho)$. When the initial values of the measured parameters were reached, the humidification cycle was repeated.

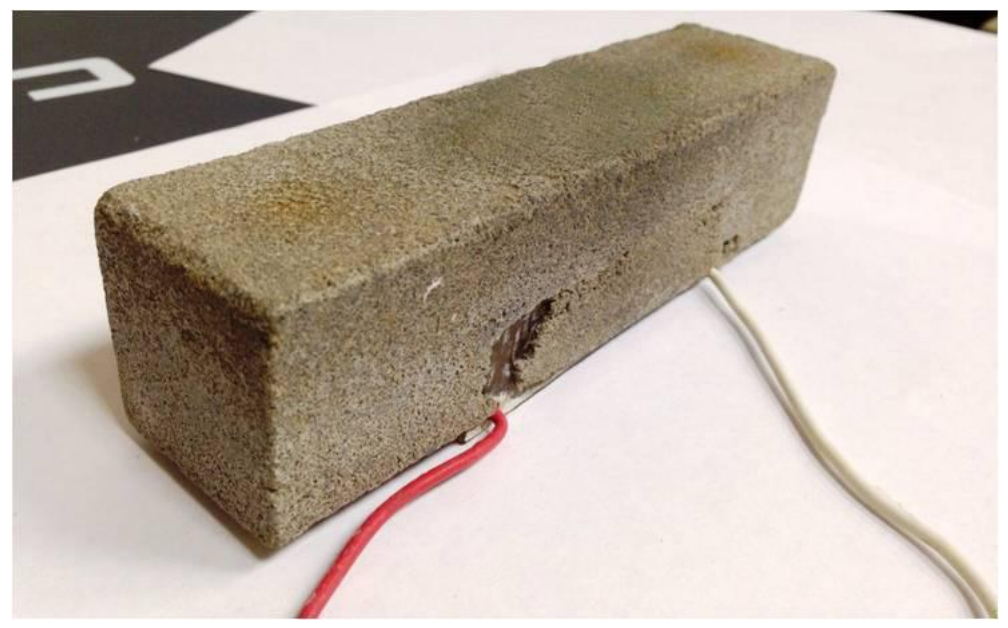

Figure 2. Bimetallic batch sensor under a layer of concrete.

Electrode potentials were measured using a $\mathrm{Canin}^{+}$instrument. Values of the electrode potentials $E_{\text {cor }}$ are given on the scale of the copper-sulfate reference electrode (CSE, the offset relative to the scale of the standard hydrogen electrode is $+0.318 \mathrm{~V}$ ). The current $\left(i_{\text {sensor }}\right)$ was measured with a specially manufactured device with zero input resistance. The value of the specific electrical resistance $(\rho)$ was monitored with the help of a four electrode sensor by the Wenner method. The geometric factor taking into account the spatial distribution of the electric field and current (cell constant) for concrete samples of the above-described form was determined in preliminary experiments and was close to 1 .

A commercially available hydrophobizator of deep penetration, based on alkoxysilanes, was used as a migrating corrosion inhibitor. The hydrophobizator also includes 2-ethylaminoethanol to give it inhibitory properties. In the future, this substance is designated GCI.

Treatment of GCI was performed after at least 3 control cycles of wetting / drying with distilled water with reproducible dependences of the value of $i_{\text {cr }}$ versus time.

\section{Results and Discussion}

The dependence of the value of $i_{\text {sensor }}$ on time consists of three characteristic regions (Figure 3). 

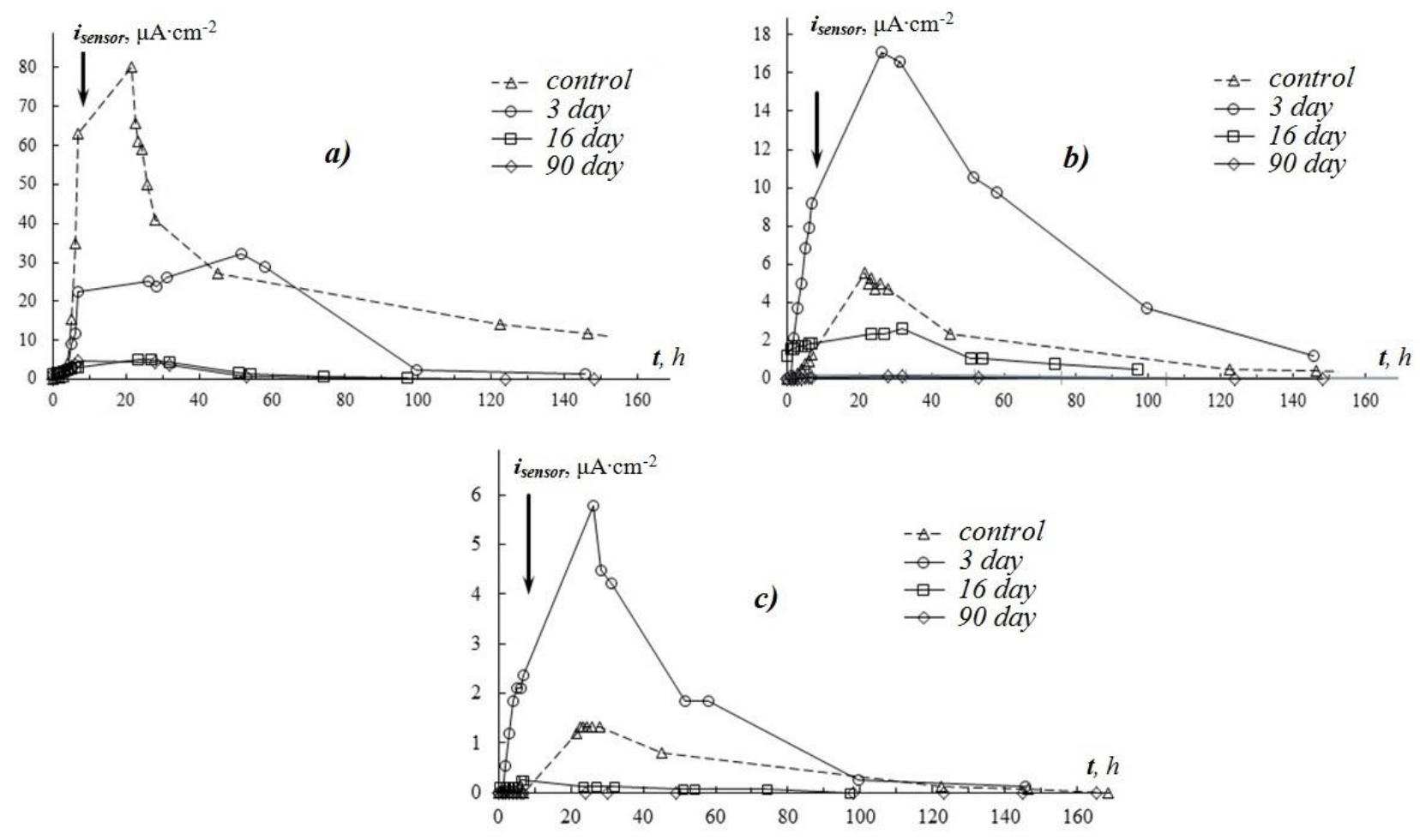

Figure 3. Time dependence current density at the sensors placed in concrete with different chloride content: $a-3.25$ mass $\% ; b-0.10$ mass $\% ; c-0.00$ mass $\%$, after treatment with a hydrophobizer. The signatures are shown in the figure, the dashed line indicates the dependencies obtained before hydrophobization. The vertical arrow corresponds to the end of humidification.

I. Induction period - time interval immediately after the beginning of the experiment. At the same time saturation of concrete with moisture. The $E_{\text {cor }}$ is shifting in the negative direction and reaches values of less than $-350 \mathrm{mV}$ corresponding to the development of corrosion with a high probability [14, 15] (Figure 3, the initial sections of the curves). The $\rho$ also decreases relative to the initial values corresponding to air-dry concrete (Figure 4, the initial sections of the curves). The value of $i_{\text {sensor }}$ during the induction period is zero or increases insignificantly on samples with a high concentration of chloride ions. The duration of this period depends on the content of chloride ions and in the conducted experiments was 3 to 7 hours.

II. The period of intensive development of the corrosion process begins immediately after the induction period and is characterized by an increase in $i_{\text {sensor }}$. This time interval covers the end of humidification and the beginning of drying. If the chloride content is more than 1.00 mass\% (hereinafter - the high chloride content), the value of $i_{\text {sensor }}$ reaches values of the order of $60 \mu \mathrm{A} \cdot \mathrm{cm}^{-2}$, which corresponds to a significant corrosion rate $(0.5-1.5 \mathrm{~mm} / \mathrm{year}$ with uniform destruction). If the content of chlorides is 0.40 mass $\%$ or less, the value of $i_{\text {sensor }}$ does not exceed units $\mu \mathrm{A} \cdot \mathrm{cm}^{-2}$. 


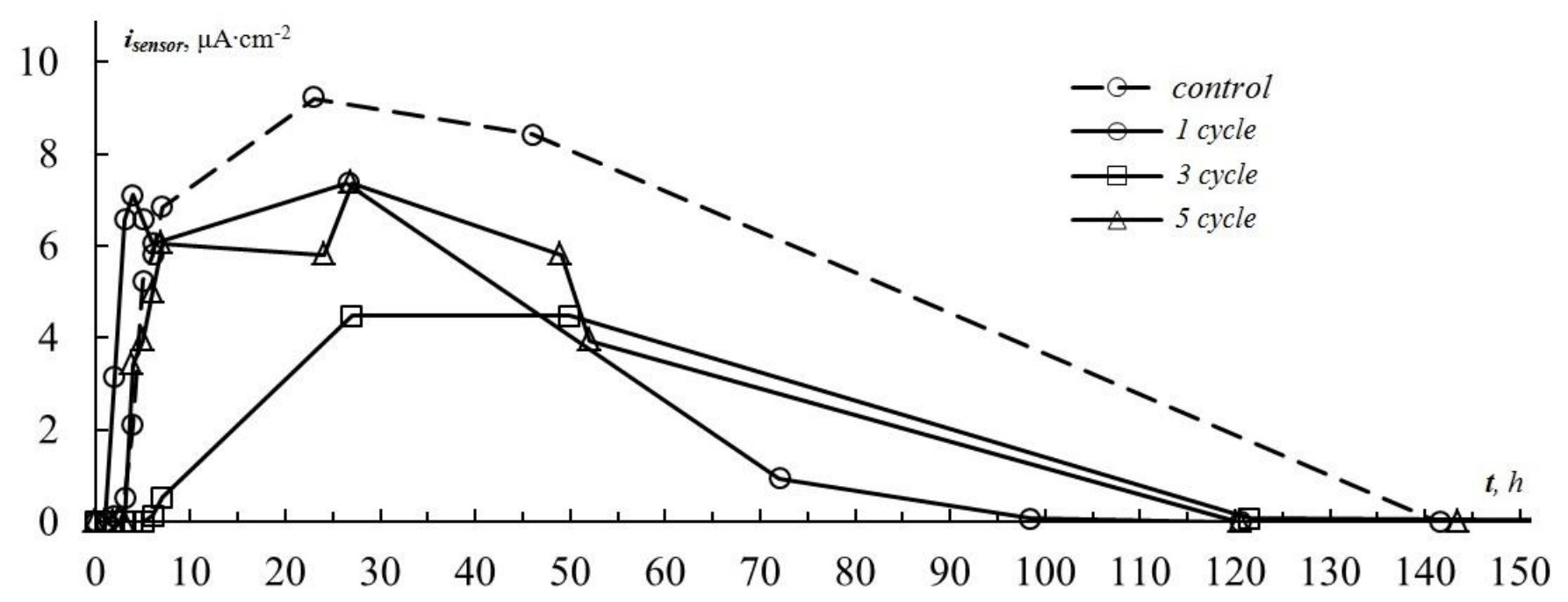

Figure 4. Time dependence current density on the sensors placed in hydrophobic concrete with a chloride content of 3.25 mass $\%$, when treated with a $3 \%$ solution of $\mathrm{NaCl}$. The captions are shown in the figure, the dashed line indicates the dependencies obtained before the treatment with a chloride solution.

Such values can be regarded as non-hazardous for the mechanical properties of the reinforcement and for the detachment of the protective layer of concrete in corrosion simulation using a bimetallic batch sensor. During the II period, the value of $E_{\text {cor }}$ continues to decrease and reaches a minimum; when the chloride content is high, it becomes less than $-500 \mathrm{mV}$. The $\rho$ also reaches a minimum. The duration of the above-described period is 1-2 days.

III. The period of decrease in the rate of corrosion begins after a certain time after the drying of the sample begins. During the III-rd period, the value of $i_{\text {sensor }}$ decreases monotonically. On samples with a low chloride content, values close to the initial values are reached within 60-70 hours. With a high chloride content, the residual value of $i_{\text {sensor }}$ is more than an order of magnitude higher than the values for the remaining samples. The $E_{\text {cor }}$ is ennobled by the end of the third period, exceeding $-200 \mathrm{mV}$ for concretes with a chloride content of 0.40 mass \% or less, which corresponds to the passive state of the reinforcement with a high probability $[14,15]$; remains in the range from -200 to $-350 \mathrm{mV}$ for concretes with a chloride content of more than 1.00 mass $\%$ - an undefined state of the metal, a "gray zone" according to $[14,15]$. For a sample with a chloride concentration of 3.25 mass $\%$, the $E_{\text {cor }}$ value remains below $-500 \mathrm{mV}$ - a high probability of a passive state of the reinforcing steel being disrupted with the formation of pitting.

With prolonged drying of concrete and a reduction in its moisture content of less than $2-4 \%$, the value of $\rho$ increases significantly, and a correct measurement of the potential for free corrosion becomes impossible. However, in this case, the values of $\rho$ for samples with 
different contents of chlorides are very different: a higher value of chlorides corresponds to a smaller value of $\rho$. The third period is the longest and can last up to several weeks.

Samples were treated with GCI after the drying cycle was completed. The first humidification cycle started after 3 days, the second and subsequent with an interval of 14-20 days. For the sake of clarity, the data of the first, second (16 days) and fifth (90 days) cycles after the treatment of concrete GCI are presented.

On samples with a chloride content of 1.00 and 3.25 mass\%, during the first humidification cycle there are no noticeable changes in the dependence of $i_{\text {sensor }}$ on time relative to the control experiment (Figure 3a). At the time of extraction of concrete samples from the desiccator (beginning of drying), the current density was reduced to 4 times with respect to the control experiment, with the subsequent retention of the stationary value for 50 hours. In the following, the value of $i_{\text {sensor }}$ decreases to almost zero values. When the experiment was repeated (the 16th day after the treatment of the GCI), the values of $i_{\text {sensor }}$ did not exceed $5-8 \mu \mathrm{A} \cdot \mathrm{cm}^{-2}$ during the entire measurement time. Similar values of the current density were recorded on the sensor in an aqueous extract of concrete without the addition of chlorides - passive state [13]. The maximum value of $i_{\text {sensor }}$ is reached at the beginning of the drying cycle, immediately after extraction from the desiccator, as in the case of control experiments Similar results were obtained during the fifth cycle (90 days after treatment of the GCI).

On samples with a low chloride content ( 0.10 and 0.40 mass $\%)$, and without the addition of chlorides, an increase in $i_{\text {sensor }}$ relative to the control sample is observed during the first cycle after hydrophobization (Figure 3b,c). The excess is $2-4$ times for the values at the maximum of the dependence of $i_{\text {sensor }}$ on the time $t$. During the second cycle, the current density during the whole experiment is lower in comparison with the control results. During the third and subsequent cycles, the current on the sensors is not fixed, the value of $i_{\text {sensor }}$ is zero, taking into account the accuracy of the measurements $\left( \pm 0.5 \mu \mathrm{A} \cdot \mathrm{cm}^{-2}\right)$.

Thus, processing of GCI of concrete samples with a chloride ion content of more than 1.00 mas $\%$ by weight is accompanied by a decrease in the value of $i_{\text {sensor }}$ on a bimetallic package sensor by $75-90 \%$, relative to reference values. It is possible to predict a similar decrease in corrosion rate on reinforcing steel on "active" areas of the surface (corrosion with formation of microcells). Depth of the sensor $(20 \mathrm{~mm})$ corresponds to the thickness of the protective layer on real structures. Consequently, the GCI is able to penetrate into the structure at distances of the order of $20 \mathrm{~mm}$ and provide a protective action with respect to the reinforcement. It should be noted that the complete suppression of the corrosion process, with a high content of chloride ions in the concrete, does not occur. Passive state of reinforcing steel at a high concentration of chloride ions is not restored.

Within the framework of a proactive strategy, the GCI can be used on structures with a high concentration of chloride ions to slow the rate of corrosion, when the passive state of reinforcing steel has already been disrupted. Based on the above data, it can be 
concluded that the period of time before the detachment of the protective layer of concrete when using the GCI will increase approximately ten-fold. These data can be used in assessing the economic feasibility of using this method of protection.

To test the stability of the protective action of the GCI, the experiment of the above procedure was carried out with the replacement of distilled water in a humidification cycle with a $3 \%$ solution of sodium chloride. After six cycles, no changes in the dependence of $i_{\text {sensor }}$ on time were found on all samples (Figure 4). Consequently, with a low chloride ion content in the structure, the use of the GCI completely suppresses the development of the corrosion process, even if there is a high concentration of chloride ions in the environment. To assess the stability of the protective action over time, it is necessary to conduct more extensive studies in the above described procedure.

In practice, the probability of developing a corrosion process is evaluated on the basis of the method for measuring the potential of free corrosion of the reinforcement. It is of interest to find out how the change in the value of $i_{\text {sensor }}$ on a bimetallic batch sensor correlates with the change in $E_{\text {cor }}$ of steel plates. The measurement of $E_{\text {cor }}$ was carried out on the sensor plates when the circuit was open. The processing of the investigated samples of the GCI is accompanied by the ennobling of the values of $E_{\text {cor }}$ (Figure 5). With a chloride ion content of 3.25 mass $\%$, the shift in the positive direction is about $100 \mathrm{mV}$ at the minimum point of the curve $E_{\text {cor }}$ versus $t$. In this case, the value of $E_{\text {cor }}$ corresponds to the active state of the steel. For concretes with a lower chloride content, a shift to the "gray zone" -200 to $-350 \mathrm{mV}$ according to the CSE scale is observed, even with the maximum moisture saturation (Figure $5 \mathrm{~b}$ ), and the transition to a zone with a low risk of corrosion $(>-200 \mathrm{mV})$ on concrete without the addition of chlorides.

Thus, the $E_{\text {cor }}$ values on samples after GCI treatment correlate well with the values of $i_{\text {sensor. }}$

After hydrophobization a significant increase in the specific electrical resistance of concrete is observed. Table 1 shows the values of $\rho$ for the control experiments and for the samples processed by the GCI. Comparison was carried out at the maximum saturation of concrete with moisture (before extraction from the desiccator). For samples without the addition of chlorides, an increase in the value of $\mathrm{p}$ is eight times, with a $\mathrm{Cl}^{-}$content of 0.10 mass $\%, 22$ times. In accordance with the criterion [16], the absolute values of $\rho$ are located in the zone of low risk of corrosion development, which is consistent with measurements of the value of $i_{\text {sensor }}$ on bimetallic batch sensors and measurements of the potential of free corrosion. With a chloride content of 3.25 mass $\%$, a 20 -fold increase in the electrical resistivity was recorded, however, the absolute value falls within the interval with an average risk of corrosion development, which also agrees with the measurements of $E_{\mathrm{cor}}$ and $i_{\text {sensor }}$. 
Table 1. Specific electrical resistance of concretes with different chloride content before and after hydrophobization.

\section{The content of chlorides in concrete, mass \% with respect to cement mass \\ $\begin{array}{ll}0.00 & 0.10\end{array}$ \\ 3.25}

\begin{tabular}{ccccc}
\hline \multirow{2}{*}{$\begin{array}{c}\text { Specific electrical } \\
\text { resistance of } \\
\text { concrete, } \Omega \cdot \mathrm{m}\end{array}$} & $\begin{array}{c}\text { Before } \\
\text { hydrophobization }\end{array}$ & 183 & 73 & 18 \\
\cline { 2 - 5 } & $\begin{array}{c}\text { After } \\
\text { hydrophobization }\end{array}$ & 1486 & 1610 & 385 \\
\hline
\end{tabular}
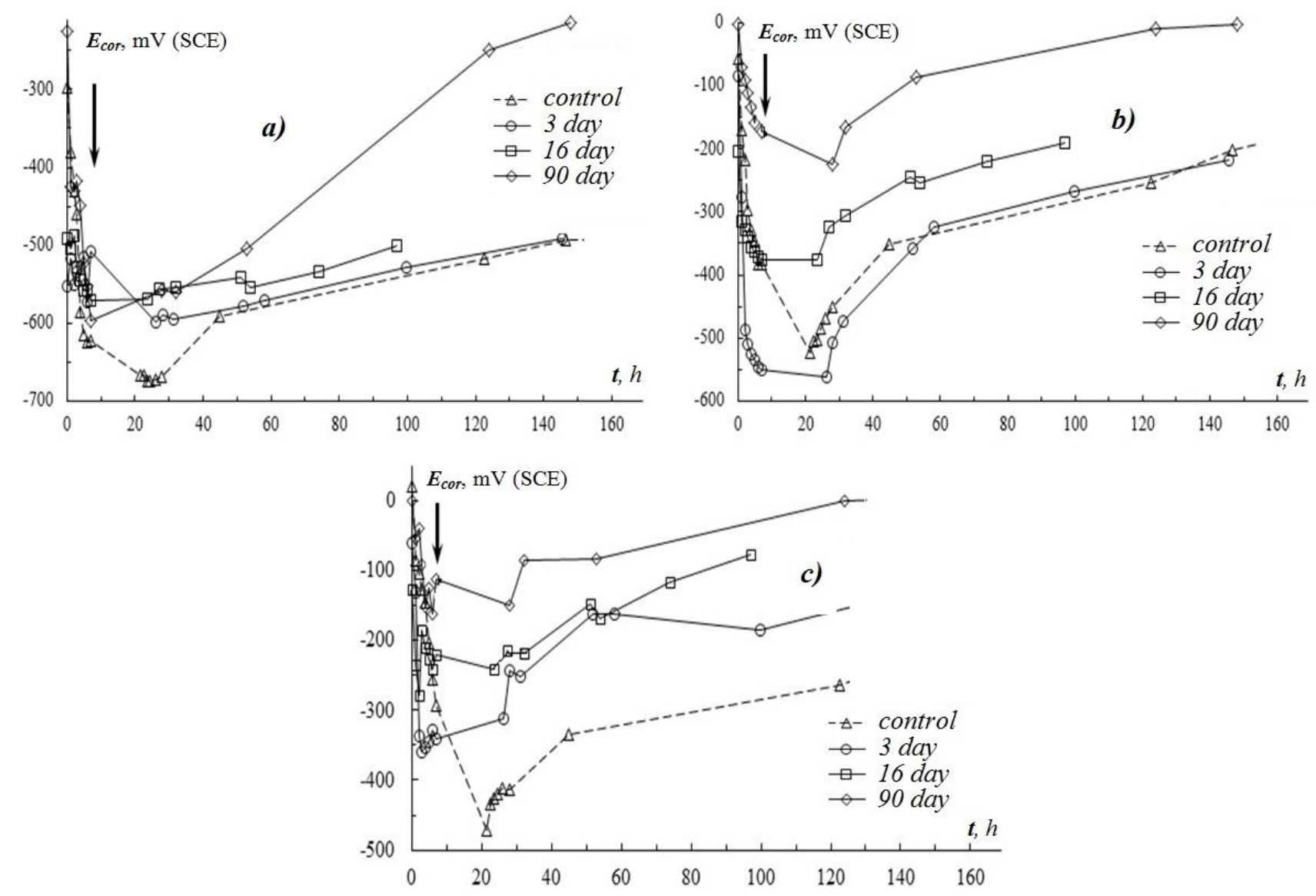

Figure 5. Time dependence the potential for free corrosion $E_{\text {cor }}$ on the sensors placed in concrete with a different content of chlorides: $a-3.25$ mass $\% ; b-0.10$ mass $\% ; c-0.00$ mass $\%$, after treatment with a hydrophobizer. The signatures are shown in the figure, the dashed line indicates the dependencies obtained before hydrophobization. The vertical arrow corresponds to the end of humidification.

Previously, it was repeatedly pointed out that there is a close relationship between the value of $\rho$ and the corrosion rate of the reinforcement [16-18]. These data served as the basis for the assumption that the ohmic resistance of concrete is the rate determining factor 
of the corrosion process. The recommendations of RILEM on the prediction of the corrosion rate of reinforcement in the field conditions have been published with the help of measuring the value of $\rho$ [16]. In the experiments described above with the use of GCI, a decrease in the $i_{\text {sensor }}$ and the increase in $\rho$, also coincide in order of magnitude. In accordance with the foregoing, it can be assumed that the corrosion process proceeds with ohmic control and the protective effect of the GCI is due to the ability of this substance to maintain a high value of $\rho$ even with a high concentration of chloride ions in the concrete.

The validity of this assumption can be estimated using simple model calculations. We assume that the copper and steel plates of the bimetallic package sensor retain the same dimensions as on the real sensor. However, they are not located in the same plane, but opposite each other at a distance equal to the thickness of the mica gasket $-0.10 \mathrm{~mm}$. In this case, all copper plates form one electrode with an area equal to the total area of all copper plates of the real sensor. The same is true for steel plates (Figure 6). The lines of the electric field and the electric current lines are uniformly distributed in space. With a similar design of the galvanic cell, the estimated value of the electric current will be the upper estimate for the actual value. When the cathode and the anode are located in the same plane, the magnitude of the current is always smaller than when they are located opposite each other (at a comparable distance between the electrodes) [19, 20].

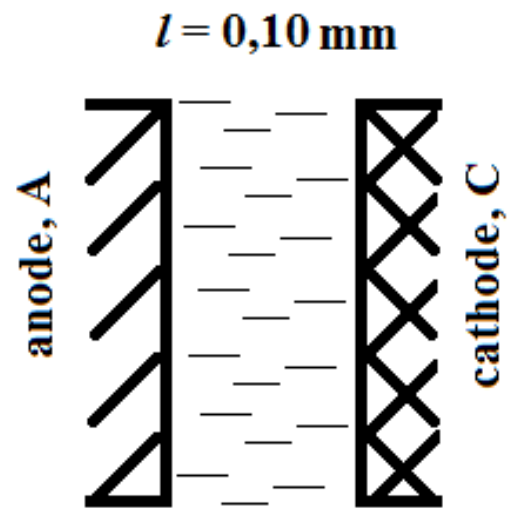

Figure 6. Location of steel and copper plates for model calculations.

The current value of the galvanic cell $\left(i_{\text {sensor }}\right)$ is determined by the combined effect of the ohmic voltage drop in the electrolyte $\left(\Delta E_{\Omega}\right)$, the polarization of the anode $P_{A}$ and the cathode $P_{C}$ according to the familiar equation:

$$
i_{\text {sensor }}=\frac{\Delta E_{0}}{R_{\Omega}+P_{\mathrm{A}}+P_{\mathrm{C}}},
$$

where $R_{\Omega}$ is the ohmic resistance of the electrolyte, $\Delta E_{0}$ is the potential difference between the cathode and the anode at zero current value. 
The rate of corrosion of the reinforcement is connected through the Faraday law with the current density $i_{\text {sensor }}$, obtained by dividing $i_{\text {sensor }}$ by the geometric area of the steel plates $S_{A}$. In this case, equation (1) is transformed to the form:

$$
i_{\text {sensor }}=\frac{\Delta E_{0}}{\rho \cdot l+P_{\mathrm{A}}^{\mathrm{s}}+P_{\mathrm{C}}^{\mathrm{s}} \cdot\left(\frac{S_{\mathrm{A}}}{S_{\mathrm{C}}}\right)},
$$

where $l$ is the distance between the cathode and the anode, $P_{\mathrm{A}}^{\mathrm{S}}$ and $P_{\mathrm{C}}^{\mathrm{S}}$ are the polarization values (polarization coefficients) normalized to the surface area (dimension $-\Omega \cdot \mathrm{cm}^{2}$ ): $P_{\mathrm{A}}^{\mathrm{S}}=P_{\mathrm{A}} \cdot S_{\mathrm{A}} ; P_{\mathrm{C}}^{\mathrm{S}}=P_{\mathrm{C}} \cdot S_{\mathrm{C}} ; S_{\mathrm{C}}$ is the area of the cathode (copper plate).

To quantify the values of $P_{\mathrm{A}}^{\mathrm{S}}$ and $P_{\mathrm{C}}^{\mathrm{S}}$, polarization diagrams were constructed directly on a bimetallic packet sensor in an aqueous extract of finely divided concrete with different concentration of chloride ions (Figure 7). The magnitude of the galvanic current was adjusted by means of a resistance box. The obtained dependences of the anode potentials (steel plates) and cathode (copper plates) on the current value are well approximated by straight lines (Figure 7). The polarization coefficients of the cathode and anode processes are presented in Table 2 and are in good agreement with the published data in order of magnitude [20].

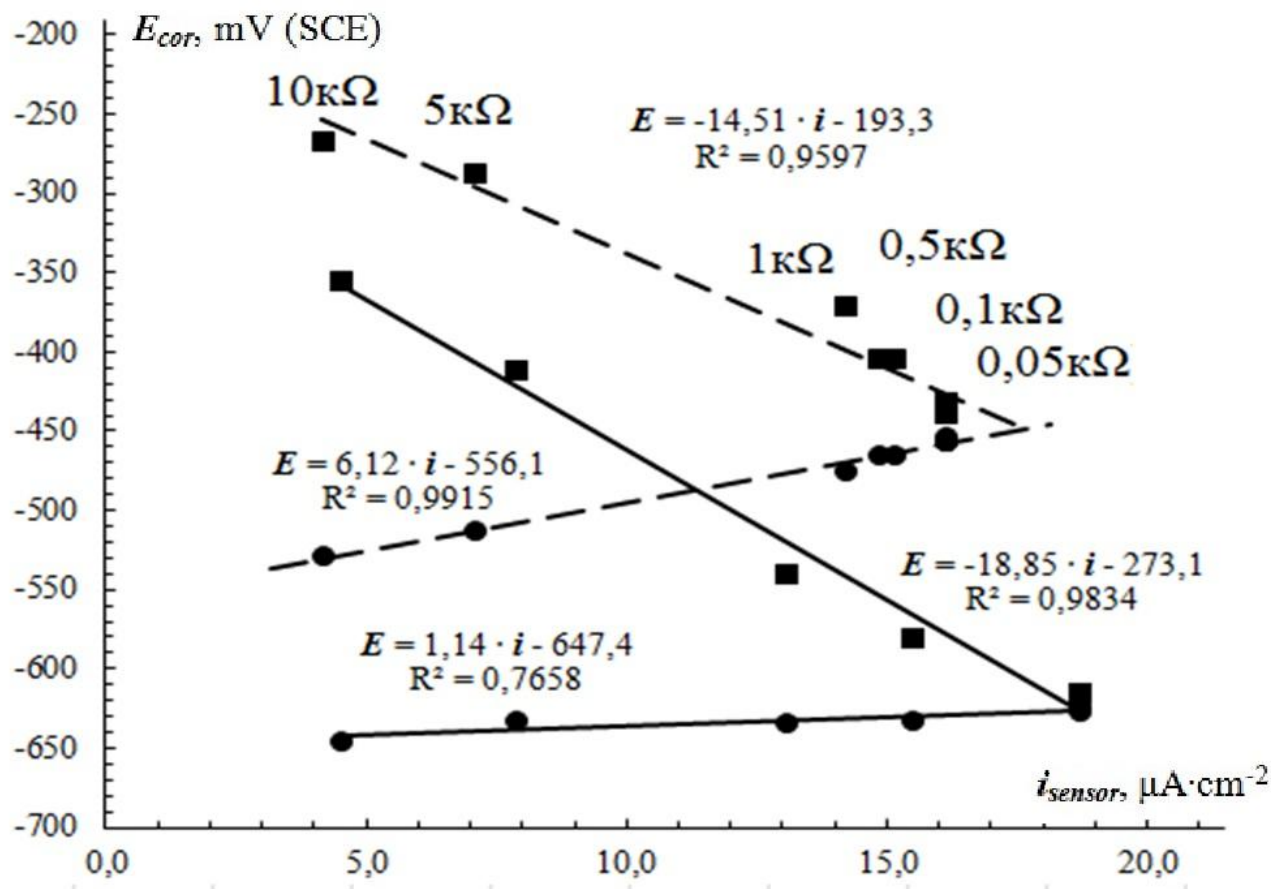

Figure 7. Dependences of the electrode potentials of steel $(\bullet)$ and copper $(\boldsymbol{\bullet})$ plates on the current density recorded at the sensor for various values of the resistance included in the circuit in an aqueous extract of concrete with different chloride content $(---0.10 \mathrm{M},-1.00 \mathrm{M})$. 
Table 2. Coefficients of polarization of cathode and anode processes on a bimetallic batch sensor.

\begin{tabular}{|c|c|c|}
\hline The content of chlorides in concrete, $\mathbf{M}$ & $\mathbf{0 . 1 0}$ & $\mathbf{1 . 0 0}$ \\
\hline$P_{\mathrm{A}}^{\mathrm{S}}, 10^{4} \Omega \cdot \mathrm{cm}^{2}$ & 6.12 & 1.14 \\
\hline$R^{2}$ for $P_{\mathrm{A}}^{\mathrm{S}}$ & 0.991 & 0.765 \\
\hline$P_{\mathrm{C}}^{\mathrm{s}}, 10^{4} \Omega \cdot \mathrm{cm}^{2}$ & 14.51 & 18.85 \\
\hline$R^{2}$ for $P_{\mathrm{C}}^{\mathrm{S}}$ & 0.959 & 0.983 \\
\hline
\end{tabular}

Taking into account the data presented in Table 1, the maximum value of the term in the denominator $\rho \cdot l$ of relation (2), for $l=1 \cdot 10^{-3} \mathrm{~m}$, is equal to $1.61 \Omega \cdot \mathrm{cm}^{2}$. This value is 4-5 orders of magnitude smaller than the coefficients of polarization of electrode reactions presented in Table 2. Consequently, the effect of the ohmic drop in the potential in the electrolyte, the pore liquid, on the magnitude of the galvanic current of the bimetallic packet sensor is negligible. It can be assumed that the mechanism of the corrosion process on the bimetallic batch sensor realistically reproduces the functioning of the microcells on steel reinforcement in concrete. Then a similar conclusion can be drawn about the effect of ohmic potential drop on the rate of corrosion of reinforcement in reinforced concrete, due to the presence of microcells. The ohmic drop in the potential could have an effect on the corrosion rate of steel reinforcement, if the value of $\rho$ was 5 orders of magnitude greater than that fixed on real structures [17]. In [21], the effect of concrete resistance on the galvanic current of a macro-pair formed by copper and steel rods, as well as copper and zinc, was analyzed. The ohmic voltage drop was determined experimentally, according to the method of current interruption. It turned out that the potential difference between the electrodes, due to the ohmic resistance of the concrete, is from 2 to $14.7 \%$ of the total potential difference between the cathode and the anode when the circuit is open. Consequently, the ohmic drop in the potential was not a factor controlling the magnitude of the current in this case.

However, the symbatical change in the values of $\rho$ and the rate of corrosion of the reinforcement remains a reliably grounded experimental fact [16]. Consequently, there must be a common cause for the changes in $\rho$ and $i_{\text {sensor }}$, explaining the consistent variation of these quantities in the absence of a causal relationship between them, expressed in the form of an explicit functional dependence similar to equation (2).

In [21] it was suggested to consider as a general reason the degree of filling of capillary pores in concrete with water. We assume that the process of corrosion of the reinforcement can only take place on parts of the metal surface in contact with water. This assumption is also true for steel plates of a bimetallic batch sensor. Therefore, it is possible to introduce a difference between the geometric surface area of the anode $S_{\AA}^{\text {geom }}$ and the 
water-contacting, hydrated $S_{\mathrm{A}}^{\text {water }}$ surface. The effective $i_{\text {sensor }}^{\text {eff }}=\frac{I_{\text {sensor }}}{S_{\mathrm{A}}^{\text {geom }}}$ and true $i_{\text {sensor }}^{\text {true }}=$ $\frac{I_{\text {sensor }}}{S_{\mathrm{A}}^{\text {water }}}$ corrosion rates correspond to the values of $S_{\mathrm{A}}^{\text {geom }}$ and $S_{\mathrm{A}}^{\text {water }}$. It is obvious that

$$
\begin{gathered}
i_{\text {sensor }}^{\text {eff }}=i_{\text {sensor }}^{\text {true }} \cdot\left(\frac{S_{\mathrm{A}}^{\text {water }}}{S_{\mathrm{A}}^{\text {geom }}}\right), \\
i_{\text {sensor }}^{\text {eff }}=\left(\frac{S_{\mathrm{A}}^{\text {water }}}{S_{\mathrm{A}}^{\text {geom }}}\right) \cdot \frac{\Delta E_{0}}{\rho \cdot l+P_{\mathrm{A}}^{\mathrm{S}}+P_{\mathrm{C}}^{\mathrm{S}} \cdot\left(\frac{S_{\mathrm{A}}}{S_{\mathrm{C}}}\right)} .
\end{gathered}
$$

With a decrease in the degree of filling of capillary pores with water, the surface area of the metal in contact with water also decreases. In this case $S_{\AA}^{\text {geom }}>S_{\mathrm{A}}^{\text {water }}$ and $i_{\text {sensor }}^{\text {eff }}<i_{\text {sensor }}^{\text {true }}$. The value of $\rho$, in turn, is a function of the water content in the concrete. But due to the negligibly small contribution of the term $\rho \cdot l$ to the denominator of equation (4), when analyzing the dependence of $i_{\text {sensor }}^{\text {eff }}$ on the time and conditions of the experiment, this term can be ignored.

Based on the above, it is possible to propose the following explanation of the experimental results described above. When processing the surface of concrete samples of GCI, this substance penetrates into the pores of concrete and hydrophobizes their surface. This changes the contact angle of wetting and part of the capillary pores is not filled with water in the humidification cycle. Therefore, the share of the surface of steel plates contacting with water and the value of the current of the galvanic cell are sharply reduced. The same mechanism of the protective effect of the GCI can also be offered in relation to steel reinforcement inside reinforced concrete structures.

\section{Conclusions}

1. It is shown that a bimetallic batch sensor can be used to simulate the corrosion process of steel reinforcement in reinforced concrete and to evaluate the efficiency of migrating corrosion inhibitors and deep penetration hydrophobizers. To justify the method, the protective effect of a commercial hydrophobizer based on alkoxysilanes containing functional groups possessing an inhibitory effect was evaluated.

2. It has been established that surface treatment of concrete samples contaminated with chlorides (1.00 and 3.25 mass\% relative to dry cement mass), studied by the hydrophobizer, leads to a sharp decrease (up to 90\%) in the corrosion rate (galvanic current at the sensor). The protective effect persists for twenty cycles of wetting/drying (10 months) and when the water in the humidification cycle is changed to a $3 \%$ solution of sodium chloride ( 6 cycles were conducted, the experiment continues). 
3. It is shown that when the concrete sample is treated with a commercial deep-penetration hydrophobizer based on alkoxysilanes, the specific electrical resistance of concrete is sharply increased (up to 20 times on samples contaminated with chlorides) and the potential for free corrosion of steel plates is shifted to positive values. Changes in the potential for free corrosion of steel plates, concrete resistivity of concrete and corrosion rate (galvanic current on the sensor) correlate well with each other.

4. The measured values of the free-corrosion potential and the resistivity of concrete meet the criteria given in RILEM TC 154-EMC for the active and passive state of the steel. As a characteristic of the transition of steel from the passive state to the active accepted rate of corrosion (galvanic current at the sensor). Therefore, measurements of the potential of free corrosion and resistivity of the protective layer of concrete can be used to determine the effectiveness of the use of hydrophobic agents in the field.

5. It is shown in the model calculations that an increase in the specific electrical resistance of the protective layer of concrete up to 10-20 times using a hydrophobizer cannot explain the significant decrease in the corrosion rate (galvanic current at the sensor). Specific electrical resistance can act as a speed-determining parameter for the corrosion process caused by microcells and modeled by the sensor, in the case of exceeding the experimental values by five or more orders of magnitude. It is suggested that a agreed change in corrosion rate and resistivity of the protective layer of concrete is due to a similar dependence of these values on the degree of filling of pores in the concrete with water.

\section{References}

1. K. Osterminski and P. Schieß1, Struct. Concr., 2012, 13, no. 3, 156. doi: 10.1002/ suco.201200003

2. K. Osterminski, Zur voll-probabilistischen Modellierung der Korrosion von Stahl in Beton, Technischen Universität München, München, 2013, p. 16.

3. J.P. Broomfield, K. Davies and K. Hladky, Cem. Concr. Compos., 2002, 24, 27.

4. D. Trejo, C. Halmen and K. Reinschmidt, Corrosion Performance Tests for Reinforcing Steel in Concrete, The Texas A\&M University SystemCollege Station, Texas, p. 16.

5. B. Elsener, M. Büchler, F. Stalderand and H. Böhni, Corrosion, 1999, 55, no. 12, 1156.

6. H.E. Jamil, A. Shriri, R. Boulif, C. Bastos, M.F. Montemor and M.G.S. Ferreira, Electrochim. Acta, 2004, 49, 2754.

7. F. Bolzoni, A. Brenna, G. Fumagalli, S. Goidanich, L. Lazzari, M. Ormellese and MP. Pedeferri, Int. J. Corros. Scale Inhib., 2014, 3, no. 4, 262. doi: 10.17675/23056894-2014-3-4-254-278 
8. M.C. Brown, Assessment of Commercial Corrosion Inhibiting Admixtures for Reinforced Concrete, Virginia Polytechnic Institute and State University, Virginia, 1999, p. 55.

9. C. Andrade and J.A. Gonzalez, Werkst. Korros., 1978, 29, 517.

10. I. Martínez and C. Andrade, Cem. Concr. Compos., 2009, 31, 548.

11. H.-W. Song and V. Saraswathy, Int. J. Electrochem. Sci., 2007, 2, 17.

12. J. Gaon, J. Wu, J. Li and X. Zhao, NDT\&E Int., 2011, 44, 203.

13. I.D. Zarcyn and D.S. Shevtsov, Korroz.: mater., zashch., 2018, no. 2, 34 (in Russian).

14. ASTM C876-91(1999), Standard Test Method for Half-Cell Potentials of Uncoated Reinforcing Steel in Concrete, ASTM International, West Conshohocken, PA, 1999. doi: $10.1520 / \mathrm{C} 0876-91 \mathrm{R} 99$

15. ODM 218.3.001-2010, Recommendations on diagnostics of active corrosion of reinforcement in reinforced concrete of bridge structures on motor ways by the halfcell potentials method, Moscow, 2010, p. 26 (in Russian).

16. R. Polder, C. Andrade, B. Ebener, O. Vennesland, J. Gulikers, R. Weidert and M. Raupach, Mater. Struct., 2000, 33, 609.

17. C. Alonso, C. Andrade and J.A. Gonzalez, Cem. Concr. Res., 1988, 8, 694.

18. F. Hunkeler, Mater. Sci. Forum, 1997，247，97. doi: 10.4028/www.scientific.net/ MSF.247.93

19. N.D. Tomashov, Theory of Corrosion and Protection of Metals, Moscow, Izd. Akad. Nauk SSSR, 1960, p. 287 (in Russian).

20. C. Andrade, I.R. Maribona, S. Feliu, J.A. Gonzalez and S. Jr. Feliu, Corros. Sci., 1992, 33, no. 2, 239.

21. S. Feliu, J.A. González, S. Jr. Feliu and C. Andrade, Br. Corros. J., 1989, 24, no. 12, 198. 